\title{
The Effect of Feeding Dried Tomato Pomace and Concentrate Feed on Body Weight Change, Carcass Parameter and Economic Feasibility on Hararghe Highland Sheep, Eastern Ethiopia
}

\section{Kefyalew Gebeyew ${ }^{1}$, Getachew Animut ${ }^{2}$, Mengistu Urge ${ }^{2}$ and Teka Feyera ${ }^{3 *}$}

1 Jigjiga University, College of Dry Land Agriculture, Jigjiga, Ethiopia

${ }^{2}$ Haramaya University, College of Agriculture and Environmental Sciences, Dire Dawa, Ethiopia

${ }^{3}$ Jigjiga University, College of Veterinary Medicine, Jigjiga, Ethiopia

\begin{abstract}
The study was conducted using 24 yearling intact Hararghe highland male sheep with mean initial body weight (BW) of $16.73 \pm 2.47 \mathrm{~kg}$ (Mean $\pm \mathrm{SD}$ ), with the objectives to evaluate the effect of supplementation of dried tomato pomace, and concentrate feed on live weight gain, carcass characteristics and economic feasibility of the feeding regime of sheep fed a basal diet of natural pasture hay. The experiment consisted 90 days feeding and followed by evaluation of carcass parameters at the end. The animals were fed concentrate at a rate of $300 \mathrm{gm}$ per day on dry matter basis. The experimental sheep were blocked into 6 blocks of 4 animals based on their initial BW and randomly assigned to one of the four treatments within a block. Four dietary treatments used in the experiment were ad libitum feeding of hay alone (T1), ad libitum feeding of hay supplemented with $359.61 \mathrm{~g}$ dried tomato pomace (DTP) (T2), ad libitum feeding of hay supplemented with $300 \mathrm{~g}$ concentrate mix (CM=33\% Noug seed cake (NSC) $+67 \%$ Wheat Bran (WB); T3), and ad libitum feeding of hay with $1: 1$ ratio mixture of DTP and concentrate mix (CM $=33 \%$ Noug seed cake (NSC) $+67 \%$ Wheat Bran (WB);T4). Average daily gain (ADG) was lowest for T1 (30 g/day), and among the supplemented treatments values for T4 (65 g/day) was numerically higher than that for T3 (58 g/day) and T2 ( $57 \mathrm{~g} /$ day). Feed conversion efficiency showed a similar trend to Average daily gain (ADG). Hot carcass weight was $6.5,8.5,8.5$ and $8.5 \mathrm{~kg}$ for $\mathrm{T} 1, \mathrm{~T} 2, \mathrm{~T} 3$ and $\mathrm{T} 4$, respectively and was lower for $\mathrm{T} 1$ than the other three treatments. Rib eye muscle area (REA) was $6.1,7.3,8.1$ and $8.2 \mathrm{~cm}^{2}(\mathrm{SEM}=0.446)$ ) for $\mathrm{T} 1, \mathrm{~T} 2, \mathrm{~T} 3$ and $\mathrm{T} 4$, respectively was significantly lower $(p<0.05)$ in T1. There was a negative net return for T1. The net return from the supplemented treatments was $62.3,5.8$, and $45.2 \mathrm{ETB}$, and the corresponding marginal rate of return was $2.49,0.54$, and $1.44 \%$ for T2, T3 and T4, respectively. Integrating this feed resource into the feeding system of sheep in areas of availability will not only solve the existing critical feed shortage, but also avoid the problem of environmental pollution. In this study, supplementation of dried tomato pomace and concentrate feed positively affected the measured growth and carcass characteristics. Therefore, the results of this study suggested that dried tomato pomace can totally replace concentrate mixture used in the present study as a supplement to sheep fed a basal diet of natural pasture hay with better economic return.
\end{abstract}

Keyword: Dried tomato pomace; Carcass parameter; Live weight gain; Economic efficiency

\section{Introduction}

Ethiopia has one of the largest livestock population in Africa with the estimated domestic animal number of 52.13 million cattle, 24.2 million sheep, 22.6 million goat, 2.5 million camels, 44.89 million poultry, 1.96 million horses, 0.37 million mules and 6.4 million donkeys [1]. Despite the large livestock population with high potential for meat and milk production, a number of factors hindered the development of livestock sector in Ethiopia. These include poor genetic potential of the indigenous animal, inadequate veterinary services, shortage of animal feeds as well as the absence of good management. Among these factors, poor feed supply and feeding system tend to have far reaching implication [2]. Diriba et al. [3] also indicated that inadequate nutrition in terms of quality and quantity is a major constraint in realizing increased ruminant production in Ethiopia.

One option for improving performance of animals fed low quality diets is supplementation with food processing agro-industrial byproducts. Tomato pomaces increasingly have been used as valuable feedstuff in ruminants and poultry nutrition in developing countries $[4,5]$. Tomato Pomace is the mixture of tomato peels, crushed seeds and small amounts of pulp that remains after the processing of tomato for juice, paste and ketchup [6].
The total area of tomato cultivation in Ethiopia is 833 ha by the year 1993 and later on the cultivation spread towards other parts of the country. Since 1994 up to present, tomato acreage increased to 5338 ha with a total production of 55,635 Metric ton [7]. Large scale production of tomato take place in the upper Awash Valley, under irrigated and rain-fed condition whereas small-scale production for fresh market is a common practice around Koka, Ziway, Wondo-Genet, Guder, Bako and many other areas [8]. In Ethiopia there are two tomato processing factories that are Melgi-Wondo and Upper Awash Agro industry. Upper Awash agro industry annually more than 234,902 quintal of tomato can be processed into tomato paste and tomato juice [9]. The

*Corresponding author: Teka Feyera, Jigjiga University, College of Veterinary Medicine, Jigjiga, Ethiopia, Tel: +251-913-199649; Fax: +251257755976; E-mail: teka841@yahoo.com

Received October 24, 2014; Accepted January 28, 2015; Published January 30, 2015

Citation: Gebeyew K, Animut G, Urge M, Feyera T (2015) The Effect of Feeding Dried Tomato Pomace and Concentrate Feed on Body Weight Change, Carcass Parameter and Economic Feasibility on Hararghe Highland Sheep, Eastern Ethiopia. J Veterinar Sci Technol 6: 217. doi:10.4172/2157-7579.1000217

Copyright: (c) 2015 Gebeyew K, et al. This is an open-access article distributed under the terms of the Creative Commons Attribution License, which permits unrestricted use, distribution, and reproduction in any medium, provided the original author and source are credited. 
Citation: Gebeyew K, Animut G, Urge M, Feyera T (2015) The Effect of Feeding Dried Tomato Pomace and Concentrate Feed on Body Weight Change, Carcass Parameter and Economic Feasibility on Hararghe Highland Sheep, Eastern Ethiopia. J Veterinar Sci Technol 6: 217. doi:10.4172/2157-7579.1000217

Page 2 of 5

objectives of this study were: To evaluate the effect of supplementation of dried tomato pomace, and concentrate on live weight gain and carcass characteristics of Hararghe highland sheep fed a basal diet of Natural pasture hay, and to evaluate the economic feasibility of tomato pomace inclusion in sheep ration.

\section{Materials and Methods}

\section{Description of the study area}

The experiment was conducted at Haramaya University which is located $515 \mathrm{~km}$ East of Addis Ababa. The site is located at an altitude of 1950 meter above sea level at $9^{\circ} 26^{\prime} \mathrm{N}$ latitude and $42^{\circ} 3^{\prime} \mathrm{E}$ longitude. The mean annual rainfall and temperature of the study area is $790 \mathrm{~mm}$ and $16^{\circ} \mathrm{C}$, respectively [10].

\section{Experimental animals and management}

Twenty four yearling intact Hararghe highland male sheep with mean initial body weight of $16.73 \pm 2.47$ (Mean \pm SD) were purchased from local market to conduct the experiment. The sheep were quarantined for 21 days in the experimental area. During this quarantine period, they were de-wormed (using Albendazole) and sprayed (using acarimic) against internal and external parasites, respectively, and vaccinated for pasteurellosis and anthrax with $1 \mathrm{ml}$ ovine vaccine and $1 / 2 \mathrm{ml}$ vaccine per sheep, respectively.

\section{Feeds and feed preparation}

Natural grass hay (predominantly Rohades grass) was harvested from Haramaya University campus, kept under hay shade to maintain its quality and used as basal diet throughout the experimental period. Processed fresh tomato pomace was collected from Merti fruit and vegetable Processing Industry (Upper Awash Agro-Industry), it was dried by spread on plastic sheet and sun dried under shade until it was crispy, packed in sacks and transported to Haramaya University. Then coarsely ground at Haramaya University feed processing mill and then kept in clean sacs.

\section{Experimental design and treatments}

A randomized complete block design (RCBD) was used for the experiment. The experimental sheep were blocked into 6 blocks of 4 animals based on their initial BW and within a block were randomly assigned to the four treatments. Treatments were: natural grass hay ad libitum alone (T1), hay ad libitum supplemented with DTP (T2), hay ad libitum supplemented with concentrate mixture of WB and NSC at a ratio of $67: 33 \%$, respectively (T3), and hay ad libitum supplemented with a 1:1 mixture of DTP (Dried Tomato Pomace) and concentrate mix (T4). The animals were fed concentrate at a rate of 300 gram per day on DM basis. The supplement for the other treatments was on isonirogenouse basis. The layout of the experimental treatments for the study is shown in Table 1.

\section{Measurements and laboratory analysis}

Body weight gain: Body weight measurements were taken every 10 days after overnight fasting and daily BW gain was determined as a difference between final and initial BW divided over the feeding days. Feed conversion ratio (FCR) was calculated as the proportion feed intake to BW gain.

Carcass measurement: At the end of the experiment, the all sheep were taken from each treatment, fasted overnight, weighed and slaughtered. Blood was collected in plastic container and weighed. The dressed carcass, edible, and non-edible offal were weighed and recorded. The cross sectional area of rib-eye muscle between the 12th and 13th rib were traced on transparent plastic sheet and measured by using a planimeter. Dressing percentage was computed as proportions of hot carcass weight to slaughter weight and empty BW.

Partial budget analysis: Partial budget analysis was used to determine the profitability of the feeding regime by the method of Upton [11]. It only involved the calculation of major cost of sheep feed (variable cost) and benefit gains from sell price of sheep without considering other cost like labor, housing and veterinary service which was common for all treatments. The calculation was done by using the formulae; Net return=Total return - Total variable cost; Marginal rate of revenue $=\Delta$ Net return $/ \Delta$ Total variable cost

\section{Statistical analysis}

Data live weight gain and carcass parameter analysis's were subjected to analysis of variance (ANOVA) using the general linear model procedure of SAS software package. The difference between treatments means were separated by using least significant difference (LSD) tests. The model for data analysis was; $\mathrm{Yij}_{-} \mu+\mathrm{t}_{\mathrm{i}}+\mathrm{b}_{\mathrm{j}}+\mathrm{e}_{\mathrm{ij}}$ Where: $\mathrm{y}_{\mathrm{ij}}=$ response variable, $\mu=$ overall mean, $\mathrm{t}_{\mathrm{i}=}$ treatment effect, $\mathrm{b}_{\mathrm{j}=}$ block effect, eij_random error

\section{Results}

\section{Body weight change and feed conversion efficiency}

The current study revealed that final BW, Body Weight Change (BWC), Average Daily Gain (ADG) and FCE were positively affected by supplementation (Table 2), and was lowest for T1 as compare to supplemented groups. Among the supplemented treatments sheep in T4 and T3 had numerically better performance in ADG and BWC compared to T2. The highest daily body weight gain $(64.8 \mathrm{~g} / \mathrm{d})$ was recorded in sheep supplemented with concentrate Mix and DTP (T2), followed by sheep in T3 $(58.3 \mathrm{~g} / \mathrm{d})$.

In general, the trend of live weight gain across feeding weeks (Figure 1) revealed that feeding for three months' time continued to increase the growth of the supplemented group progressively. Increase in live weight and ADG in sheep supplemented with T2, T3 and T4 may be attributed to the supplemented feed provided as compared to the control. As the amount of feed consumed increased, the level

\begin{tabular}{|c|c|c|c|}
\hline \multicolumn{4}{|c|}{ Supplements (g/day/animal) on DM basis } \\
\hline Treatments & Hay & Dried Tomato pomace & Concentrate mix \\
\hline $\mathrm{T}_{1}$ & Ad libitum & 0 & 0 \\
\hline $\mathrm{T}_{2}$ & Ad libitum & $359.61 \mathrm{~g}$ & 0 \\
\hline $\mathrm{T}_{3}$ & Ad libitum & 0 & $300 \mathrm{~g}$ \\
\hline $\mathrm{T}_{4}$ & Ad libitum & $179.6 \mathrm{~g}$ & $150 \mathrm{~g}$ \\
\hline
\end{tabular}

Concentrate $\mathrm{mix}=33 \%$ noug seed cake and $67 \%$ wheat bran; $\mathrm{DM}=$ dry matter.

Table 1: Experimental treatments.

\begin{tabular}{|c|c|c|c|c|c|c|}
\hline \multicolumn{7}{|c|}{ Treatments } \\
\hline Variables & T1 & T2 & T3 & T4 & SEM & SL \\
\hline Initial BW $(\mathrm{kg})$ & 16.2 & 17.4 & 16.6 & 16.8 & 0.537 & Ns \\
\hline Final BW (kg) & $18.8^{\mathrm{b}}$ & $22.6^{\mathrm{a}}$ & $21.8^{\mathrm{a}}$ & $22.6^{\mathrm{a}}$ & 0.788 & $* *$ \\
\hline ADG (g/day) & $29.6^{\mathrm{b}}$ & $57.4^{\mathrm{a}}$ & $58.3^{\mathrm{a}}$ & $64.8^{\mathrm{a}}$ & 4.75 & $* * *$ \\
\hline FCE (g ADG/g DMI) & $0.053^{\mathrm{b}}$ & $0.083^{\mathrm{a}}$ & $0.090^{\mathrm{a}}$ & $0.095^{\mathrm{a}}$ & 0.0067 & $* *$ \\
\hline
\end{tabular}

${ }^{a-c}$ means with different superscripts in a row are significantly different at ${ }^{* * *}(\mathrm{P}<0.001) ;{ }^{* *}(\mathrm{P}<0.01) ;{ }^{*}(\mathrm{P}<0.05) ; \mathrm{Ns}=$ non-significant.

Table 2: Body weight change of Hararghe highland sheep fed natural pasture grass hay basal diet and supplemented with dried tomato pomace and concentrate feed 
Citation: Gebeyew K, Animut G, Urge M, Feyera T (2015) The Effect of Feeding Dried Tomato Pomace and Concentrate Feed on Body Weight Change, Carcass Parameter and Economic Feasibility on Hararghe Highland Sheep, Eastern Ethiopia. J Veterinar Sci Technol 6: 217. doi:10.4172/2157-7579.1000217

Page 3 of 5

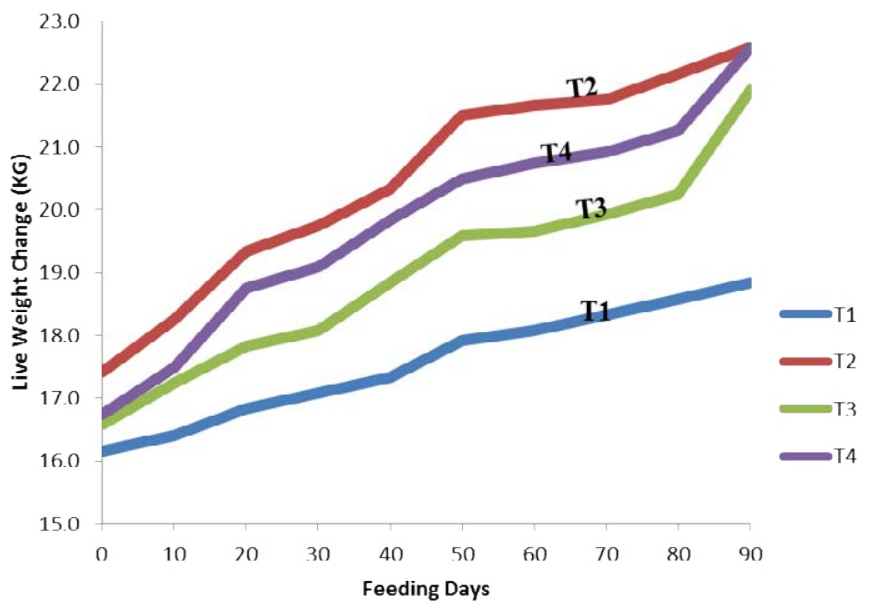

Figure 1: BW during the feeding trial for Hararghe highland sheep fed natural pasture grass hay basal diet supplemented with dried tomato pomace and concentrate feed.

of nutrient obtained increases and the increment of feed intake has a positive effect on live weight.

\section{Carcass component}

Slaughter weight took similar pattern like that of final BW (Table 3). Empty body weight, hot carcass weight, and weight of loin, forelegs, hind legs, and neck were all lower for T1 as compared to the supplemented treatments which were similar among them. Dressing percentage on slaughter BW basis was higher for T3, while values for T4 and T2 was similar $(\mathrm{P}<0.01)$. Dressing percentage on empty BW basis as well as brisket weight were similar $(\mathrm{P}>0.05)$ among treatments. In this study, supplementation with dried tomato pomace and concentrate feed positively affected the measured carcass characteristics. Rib-eye muscle area was lower for $\mathrm{T} 1$ than $\mathrm{T} 3$ and $\mathrm{T} 4$, while value for $\mathrm{T} 2$ was similar with the other three treatments.

\section{Non-carcass components}

In the present study, blood, empty gut, heart, reticulo-rumen, omaso-abomasum, tail, and tongue weights were similar $(\mathrm{P}>0.05)$ among treatments. Weight of liver and kidney were lower for the nonsupplemented treatments as compared to the supplemented ones. Generally, heart fat, kidney fat and omental fat appeared to be lower for the non-supplemented sheep. Total edible offal (TEO) was significantly higher $(\mathrm{P}<0.01)$ in the supplemented than non-supplemented one, but no significant difference in among the supplemented groups (Table 4 ).

Non-edible offal's component of sheep used in the experiment are presented in Table 5. There was no significant $(\mathrm{P}>0.05)$ difference in the weight of feet, spleen, testicles, large intestine, small intestine and lung with trachea among treatments. Head without tongue was lower for $\mathrm{T} 1$ as compared to the supplemented treatments. The gut content was higher for T1, T2 and T4 than T3, possibly due to the higher fiber content of the basal diet and dried tomato pomace. The weight of the skin and penis appeared to be improved by supplementation. Generally, there was no significant difference among treatments for most non-edible offal's in the current study.

\section{Partial budget analysis}

The cost of feeds and materials used in the experiment and the result of partial budget analysis was shown in Table 6 . The analysis considered major costs and return per head of Hararghe highland sheep. This study showed that loss of 42.9 ETB per animal for the control treatment. The supplemented sheep group (T2) and (T4) had higher net return as compared to T3. The higher profit obtained in T2 and T4. The values of MRR (Marginal Rate of Revenue) of the present study are positive for supplemented groups.

\section{Discussion}

\section{Body weight change and feed conversion efficiency}

Initial body weight was similar $(\mathrm{P}>0.05)$ among treatments. The hay used in current study was of good quality in which could have been a reason for the positive and good ADG observed for T1 in this study. Sheep fed hay alone showed lower ADG which could be due to lower DM and CP intake. Values for FCE for T1 was with the in range of $0.042-0.079$ obtained by Niguse [12] in sheep fed natural hay basal diet. The enhanced FCE in the supplemented group in the current study seems to be related to higher nutrient concentration of the supplements and the consequent increase in live weight gain. In agreement to the result of this study, Tesfay and Solomon [13] and Fentie and Solomon [14] also reported supplemented sheep to have higher FCE than the non-supplemented ones.

\begin{tabular}{|c|c|c|c|c|c|c|}
\hline \multicolumn{7}{|c|}{ Treatments } \\
\hline Variables & T1 & T2 & T3 & T4 & SEM & SL \\
\hline Empty body weight $(\mathrm{kg})$ & $13^{\mathrm{b}}$ & $16.8^{\mathrm{a}}$ & $17^{\mathrm{a}}$ & $17.2^{\mathrm{a}}$ & 0.651 & $* * *$ \\
\hline Hot carcass weight $(\mathrm{kg})$ & $6.5^{\mathrm{b}}$ & $8.5^{\mathrm{a}}$ & $8.5^{\mathrm{a}}$ & $8.5^{\mathrm{a}}$ & 0.379 & $* *$ \\
\hline Dressing \% per SW & $34.3^{\mathrm{c}}$ & $37.3^{\mathrm{b}}$ & $38.8^{\mathrm{a}}$ & $37.3^{\mathrm{b}}$ & 0.0079 & $* *$ \\
\hline Dressing \% per EBW & 50.3 & 50.7 & 50.4 & 51.7 & 0.015 & Ns \\
\hline Loin weight $(\mathrm{kg})$ & $1.3^{\mathrm{b}}$ & $1.7^{\mathrm{a}}$ & $1.6^{\mathrm{a}}$ & $1.7^{\mathrm{a}}$ & 0.099 & $*$ \\
\hline Forelegs $(\mathrm{kg})$ & $1.2^{\mathrm{b}}$ & $1.6^{\mathrm{a}}$ & $1.6^{\mathrm{a}}$ & $1.5^{\mathrm{a}}$ & 0.087 & $*$ \\
\hline Hind legs $(\mathrm{kg})$ & $1.5^{\mathrm{b}}$ & $2.1^{\mathrm{a}}$ & $2.1^{\mathrm{a}}$ & $2.1^{\mathrm{a}}$ & 0.098 & \multirow{2}{**}{} \\
\hline Brisket $(\mathrm{kg})$ & 0.58 & 0.55 & 0.53 & 0.59 & 0.061 & Ns \\
\hline Ribs with muscle $(\mathrm{kg})$ & $0.88^{\mathrm{c}}$ & $1.3^{\mathrm{b}}$ & $1.4^{\mathrm{a}}$ & $1.3^{\mathrm{b}}$ & 0.049 & $* * *$ \\
\hline Rib eye area $\left.(\mathrm{cm})^{2}\right)$ & $6.1^{\mathrm{b}}$ & $7.3^{\mathrm{ab}}$ & $8.1^{\mathrm{a}}$ & $8.2^{\mathrm{a}}$ & 0.446 & $*$ \\
\hline Neck $(\mathrm{kg})$ & $0.55^{\mathrm{b}}$ & $0.77^{\mathrm{a}}$ & $0.70^{\mathrm{a}}$ & $0.75^{\mathrm{a}}$ & 0.031 & $* * *$ \\
\hline
\end{tabular}

a-c means in the same in a row with different superscript differ significantly; ${ }^{* * *}(p<0.001) ;{ }^{* *}(p<0.01) ;{ }^{*}(P<0.05) ; N s=$ non-significant

Table 3: Main carcass characteristics of Hararghe highland sheep fed natura pasture grass hay basal diet and supplemented with DTP and concentrate feed.

\begin{tabular}{|c|c|c|c|c|c|c|}
\hline \multicolumn{7}{|c|}{ Treatments } \\
\hline Edible offal & T1 & T2 & T3 & T4 & SEM & SL \\
\hline Blood $(g)$ & 489.62 & 606.82 & 699.27 & 569.00 & 43.70 & Ns \\
\hline Empty gut $(\mathrm{kg})$ & 1.1 & 1.4 & 1.4 & 1.4 & 0.082 & Ns \\
\hline Heart $(\mathrm{g})$ & 57.28 & 63.98 & 63.2 & 62.6 & 4.89 & Ns \\
\hline Heart fat $(\mathrm{g})$ & $24.53^{\mathrm{c}}$ & $29.32^{\mathrm{bc}}$ & $41.22^{\mathrm{a}}$ & $36.47^{\mathrm{ab}}$ & 2.65 & $* *$ \\
\hline Liver $(\mathrm{g})$ & $228.5^{\mathrm{b}}$ & $311.5^{\mathrm{a}}$ & $311.6^{\mathrm{a}}$ & $330.0^{\mathrm{a}}$ & 17.79 & $* *$ \\
\hline Kidney $(\mathrm{g})$ & $44.5^{\mathrm{b}}$ & $52.98^{\mathrm{a}}$ & $55.8^{\mathrm{a}}$ & $52.5^{\mathrm{a}}$ & 1.99 & $* *$ \\
\hline Kidney fat $(\mathrm{g})$ & $31.0^{\mathrm{b}}$ & $74.6^{\mathrm{a}}$ & $47.3^{\mathrm{b}}$ & $68.9^{\mathrm{a}}$ & 6.89 & $* *$ \\
\hline Reticulo-rumen $(\mathrm{g})$ & 380.6 & 386.7 & 370.7 & 336.9 & 22.03 & Ns \\
\hline Omental fat $(\mathrm{g})$ & $27.2^{\mathrm{c}}$ & $75.9^{\mathrm{b}}$ & $82.6^{\mathrm{b}}$ & $125.9^{\mathrm{a}}$ & 22.03 & $* * *$ \\
\hline Omaso-abomasum $(\mathrm{g})$ & 110.1 & 141.6 & 132.4 & 147.9 & 12.89 & Ns \\
\hline Tail $(\mathrm{kg})$ & 0.301 & 0.540 & 0.591 & 0.585 & 0.100 & Ns \\
\hline Tongue $(\mathrm{g})$ & 55.5 & 64.8 & 59.7 & 58.9 & 2.89 & Ns \\
\hline TEOC $(\mathrm{kg})$ & $2.86^{\mathrm{b}}$ & $3.78^{\mathrm{a}}$ & $3.85^{\mathrm{a}}$ & $3.76^{\mathrm{a}}$ & $0.22^{\mathrm{a}}$ & $*$ \\
\hline
\end{tabular}

${ }^{a-c}$ mean in the same row with different superscript differ significantly; ${ }^{* * *}(p<0.001)$; ${ }^{* *}(p<0.01) ;{ }^{*}(P<0.05) ;$ Ns=non-significant.

Table 4: Edible offal components of Hararghe highland sheep fed natural pasture grass hay basal diet and supplemented with dried tomato pomace and concentrate feed. 
Citation: Gebeyew K, Animut G, Urge M, Feyera T (2015) The Effect of Feeding Dried Tomato Pomace and Concentrate Feed on Body Weight Change, Carcass Parameter and Economic Feasibility on Hararghe Highland Sheep, Eastern Ethiopia. J Veterinar Sci Technol 6: 217. doi:10.4172/2157-7579.1000217

Page 4 of 5

\begin{tabular}{|c|c|c|c|c|c|c|}
\hline \multicolumn{7}{|c|}{ Treatments } \\
\hline Non-edible offal & T1 & T2 & T3 & T4 & SEM & SL \\
\hline Head without tongue $(\mathrm{kg})$ & $1.1^{\mathrm{b}}$ & $1.3^{\mathrm{a}}$ & $1.3^{\mathrm{a}}$ & $1.3^{\mathrm{a}}$ & 0.037 & *** \\
\hline Feet $(\mathrm{g})$ & 312 & 371.6 & 331.6 & 344.2 & 18.73 & Ns \\
\hline Gut content (kg) & $5.8^{\mathrm{a}}$ & $5.9^{\mathrm{a}}$ & $4.9^{\mathrm{b}}$ & $5.4^{\mathrm{a}}$ & 0.25 & ** \\
\hline Penis (g) & $54.5^{\mathrm{c}}$ & $80.2^{\mathrm{ab}}$ & $67.0^{\mathrm{bc}}$ & $92.7^{\mathrm{a}}$ & 8.43 & * \\
\hline Spleen (g) & 22.7 & 29.6 & 32.3 & 30.5 & 2.44 & Ns \\
\hline Skin (kg) & $1.3^{\mathrm{c}}$ & $1.8^{\mathrm{ab}}$ & $1.6^{\mathrm{bc}}$ & $2.0^{\mathrm{a}}$ & 0.092 & *** \\
\hline Testicles (g) & 179.5 & 229.8 & 279.7 & 179.8 & 19.31 & Ns \\
\hline Lung with trachea $(\mathrm{g})$ & 248.27 & 245.7 & 383.07 & 265.15 & 15.98 & Ns \\
\hline small intestine $(\mathrm{g})$ & 339.6 & 358.1 & 406.7 & 363.7 & 60.23 & Ns \\
\hline large intestine (g) & 102.3 & 190.2 & 207 & 201.2 & 28.94 & Ns \\
\hline NEOC (kg) & $9.49^{\mathrm{ab}}$ & $10.5^{\mathrm{a}}$ & $9.52^{\mathrm{b}}$ & $10.23^{\mathrm{a}}$ & 0.37 & \\
\hline
\end{tabular}

a-d mean in the same row with different superscript differ significantly; ${ }^{* * *}(p<0.001)$; ${ }^{* *}(p<0.01) ;{ }^{*}(P<0.05)$; Ns=non-significant.

Table 5: Non-edible offal components of Hararghe highland sheep fed natural pasture grass hay basal diet and supplemented with dried tomato pomace and concentrate feed

\begin{tabular}{|c|c|c|c|c|}
\hline \multicolumn{5}{|c}{ Treatments } \\
\hline Variables & T1 & T2 & T3 & T4 \\
\hline Purchase price per sheep (ETB) & 305 & 307.5 & 305.8 & 305.7 \\
\hline Hay consumed (kg/sheep) & 48.3 & 29.9 & 32.5 & 29 \\
\hline NSC consumed (kg/sheep) & - & - & 8.9 & 4.5 \\
\hline WB consumed (Kg/sheep) & - & - & 18.1 & 9.1 \\
\hline DTP consumed (kg/sheep) & - & 35.7 & - & 17.8 \\
\hline Feed costs & & & & \\
\hline Cost of NSC (ETB/sheep) & - & - & 44.5 & 22.5 \\
\hline Cost of hay (ETB/sheep) & 82.9 & 51.3 & 55.7 & 49.7 \\
\hline Cost of WB (ETB/sheep) & - & - & 72.4 & 36.4 \\
\hline Cost of DTP (ETB/sheep) & - & 71.4 & - & 34.8 \\
\hline TVC (ETB/sheep) & 387.9 & 430.2 & 478.4 & 449.1 \\
\hline Gross return (ETB/sheep) & 650 & 800 & 790 & 800 \\
\hline Total return (TR) (ETB/sheep) & 345 & 492.5 & 484.2 & 494.3 \\
\hline Net return (ETB/sheep) & -42.9 & 62.3 & 5.8 & 45.2 \\
\hline Change in total return (ETB/sheep) & - & 147.5 & 139.2 & 149.3 \\
\hline Change in net income $(\Delta \mathrm{NI})(\mathrm{ETB} / \mathrm{sheep})$ & - & 105.2 & 48.7 & 88.1 \\
\hline Change of total variable cost $(\Delta \mathrm{TVC})$ & - & 42.3 & 90.5 & 61.2 \\
\hline MRR $(\Delta \mathrm{NI} / \Delta \mathrm{TVC})$ & - & 2.49 & 0.54 & 1.44 \\
\hline
\end{tabular}

$\mathrm{ETB}=$ Ethiopian birr; $\Delta \mathrm{NI}=$ change in net income; $\Delta \mathrm{TVC}=$ change of total variable cost.

Table 6: Partial budget analysis for Hararghe Highland sheep fed native hay and supplemented with dried tomato pomace and concentrate feed.

\section{Carcass component}

According to the result of the present study, slaughter weight (SW) and empty body weight (EBW), and Dressing percentage on empty BW of the supplemented groups was higher as compared to the control. In this study, supplementation with dried tomato pomace and concentrate feed positively affected the measured carcass characteristics. Accordingly, the relative weight of primal cuts has been improved by supplementation which obviously is a consequence of greater empty body weight of the supplemented animals $[15,16]$. The Rib-eye muscle area was significantly higher for T3 and T4 than the control. Rib-eye muscle area is an indirect measurement of body musculature and amount of lean meat in the carcass [17]. Rib eye muscle area is positively correlated with slaughter weight $[18,19]$, which can be impacted by nutrition. The Rib-eye muscle area of the present study were comparable to values reported by Hirut [20] for
Hararghe highland sheep $\left(3.7-8.4 \mathrm{~cm}^{2}\right)$ fed basal diet of urea treated maize stover and supplemented with increasing level of concentrate diet.

\section{Non-carcass components}

In the present study, heart fat, kidney fat and omental fat appeared to be lower for the non-supplemented sheep. Riley et al. [21] indicated that differences in internal organs is more influenced by age, breed and sex of the animals rather than plane of nutrition while the amount of fat deposit is highly correlated with plane of nutrition or energy content of the diet and appropriate dietary energy-protein combinations [22]. On the other hand, the increase in liver weight with supplementation might be related to the storage of reserve substances such as glycogen as described by Lawrence and Fowler [23].

There was no significant difference among treatments for most non-edible offal's in the current study, which is supported by Pena et al. [24] who stated that relative proportion of non-carcass components significantly decrease relative to increment in the size of live weight. The lack of significant difference for non-edible offal's observed in this study is consistent with that noted by others [20]. Conversely, Abebe [25] reported heavier total non-edible offal's for supplemented ArsiBale sheep than the non-supplemented sheep fed basal diet of grass hay.

\section{Partial budget analysis}

The analysis considered major costs and return per head of Hararghe highland sheep. This study showed that loss of 42.9 ETB per animal for the control treatment. The reasons for the negative net return might be due to less body weight gain, the relatively poor general physical appearance, as a result of lower nutrient intake of the un-supplemented group.

The difference in the net return among the supplemented treatments was mainly due to the higher difference in feed cost of the supplements, and selling price of the animals in each treatment. The higher profit obtained in T2 and T4 is due to the lower cost of dried tomato pomace ( $2 \mathrm{Birr} / \mathrm{kg}$ ), better FCE and ADG of the sheep in these treatments, which resulted in higher selling price. On the other hand, the net income of sheep in T3 was lower which was affected by the high cost of Noug Seedcake (NSC) (5 Birr/kg) and wheat Bran (WB) (4 birr $/ \mathrm{kg}$ ). The values of MRR (Marginal Rate of Revenue) of the present study are positive for supplemented groups. The MRR showed that each additional unit of one ETB (Ethiopia Birr) per sheep cost increment resulted in one ETB and additional 2.49, 0.54 and 1.44 ETB benefit for T2, T3 and T4, respectively.

\section{Conclusion}

The present work evidenced that integrating this feed resource into the feeding system of sheep in areas of availability will not only solve the existing critical feed shortage, but also avoid the problem of environmental pollution. In this study, supplementation of dried tomato pomace and concentrate feed positively affected the measured growth and carcass characteristics. Thus, it could be suggested that dried tomato pomace can replace the amount and type of concentrate mixture used in the present study to supplement sheep fed a basal diet of hay with good growth, Carcass yield and better economic return

\section{Acknowledgements}

The authors' heartfelt appreciation goes to the Ethiopian Ministry of Education for partly funding this project and Haramaya University for provision of research facilities. 
Citation: Gebeyew K, Animut G, Urge M, Feyera T (2015) The Effect of Feeding Dried Tomato Pomace and Concentrate Feed on Body Weight Change, Carcass Parameter and Economic Feasibility on Hararghe Highland Sheep, Eastern Ethiopia. J Veterinar Sci Technol 6: 217. doi:10.4172/2157-7579.1000217

\section{References}

1. CSA (Central Statistics Authority) (2012) Federal Democratic Republic of Ethiopia, Agricultural sample survey on livestock and livestock production (Private peasant holdings), Statistical Bulletin No. 532, Addis Ababa, Ethiopia 2. $9-20$

2. Alemayehu M (2002) Forage Production in Ethiopia: A case study with emphasis for livestock production, ESAP. Page 120. Publication No. 3. Addis Ababa, Ethiopia.

3. Diriba G, Diriba D, Jemal D (2004) Forage Productivity and Compatibility of mixtures of Chlories gayana and Panicum coloratum with Desmodium unicenatum at Bako, Western Ethiopia. PP.173-180. Proceedings of the 12th Annual Conference of the Ethiopian Society of Animal Production (ESAP). Addis Ababa, Ethiopia.

4. Aghajanzadeh-Golshani A, Maheri-Sis N, Mirzaei-Aghsaghali A, BaradaranHasanzadeh A (2010) Comparison of nutritional value of tomato pomace and brewer's grain for ruminants using in vitro gas production technique. Asian Journal of Animal and Veterinary Advance, 5: 43-51.

5. Yuanglang $C$, Vasupen $K$, Wongsuthavas $S$, Panyakaew $P$, Alhaidary $A$ Mohamed H E, Beynen A C (2010) Growth performance in beef cattle fed rations containing dried tomato pomace. Journal of Animal and Veterinary Advance 9: 2261-2264.

6. Ventura MR, Pieltin MC, Castanon JIR (2009) Evaluation of tomato crop byproducts as feed for goats. Animal Feed Science and Technology 154: 271 275

7. FAO (Food and Agricultural Organization) (2012) Crop and Food Security Assessment Mission to Ethiopia. Special report. Food and Agriculture Organization of the United Nations, Rome, Italy.

8. Lemma D, Yayeh Z, Herath E (1992) Agronomic Studies in Tomato and Capsicum. In; Herath and Lemma (eds). Horticulture Research and Development in Ethiopia. 1-3 December. Addis Ababa, Ethiopia. Pp. 153-163.

9. UAAI (Upper Awash Agro industry) (2009) Amount of Processing Tomato Unpublished progress report 1. Upper Awash Agro Industry, Merti.

10. Mishra BB, Kidan HG, Kibret K, Assen M, Eshetu B (2004) Soil and land resource inventory at Alemaya University Research Farm with reference to land evaluation for sustainable agricultural management and production. Synthesis of working papers, Soil Science Bulletin No. 1. Alemaya University, Alemaya, Ethiopia.

11. Upton M (1979) Farm management in Africa: the principle of production and planning. Oxford University press, Great Britain. Pp. 282-298.

12. Niguse G (2011) Effects of supplementing Euphorbia tirucalli, Acacia albida pods and their mixtures on feed intake, body weight gain, digestibility and carcass characteristics of Abergelle goats fed on native hay basal diet. MSc Thesis Presented to the School of Graduate Studies of Haramaya University, Ethiopia
13. Tesfay $H$, Solomon $M$ (2009) Feed intake, digestibility, body weight and carcass parameters of Afar rams fed tef (Eragrostis tef) straw supplemented with graded level of concentrate mix. Tropical Animal Health Production, 41 : 599-611.

14. Fentie B, Solomon M (2008) Effect of supplementation of hay with noug seed their mixture on feed intake, digestibility, live weight change, and carcass characteristics in live weight change in Farta sheep.

15. Karim SA, Tripathi MK, Singh VK (2007) Effect of varying level of concentrate supplementation on growth performance and carcass traits of finishing lambs. Livestock Research for Rural Development, 19: 11

16. Galvani DB, Pires CC, Wommer TP, F de Oliverira, Bolzan AMS, et al. (2008) Carcass traits of feedlot crossbred lambs slaughtered at different live weights. Ciencia Rural, Santa Maria. 38: 1711-1717.

17. Wolf BT, Smith C, Sales DI (1980) Growth and carcass composition in the crossbred progeny of six terminals sire breeds of sheep. Journal of Animal production, 31: 307-313.

18. Park GB, Moon SS, Ko YD, Ha JK, Lee JG, et al. (2002) Influence of slaughter weight and sex on yield and quality grades of Hanwoo (Korean native cattle) carcasses. Journal of Animal Sciences, 80: 129-136.

19. Fernandes MHMR, Resende KT, Tedeschi LO, Fernandes JS, Teixeira IAMA et al. (2008) Predicting the chemical composition of the body and the carcas of $34^{\text {th }}$ Bore $\times 14^{\text {th }}$ Saanen Kids using body components. Small Ruminant Research, 75: 90-98

20. Hirut $Y$ (2008) Supplementation of concentrate mix to Hararghe Highland sheep fed a basal diet of urea- treated maize Stover; effect on feed utilization, live weight change and carcass characteristics. MSc Thesis Presented to School of Graduate Studies of Haramaya University, Haramaya, Ethiopia.

21. Riley RR, Savell JW, Shelton M, Smith GC (1989) Carcass and offal yields of sheep and goats as influenced by market class and breed. Small Ruminant Research, 2: 265-272.

22. Archimede H, Pellonde P, Despois P, Etienne T, Alexandre G (2008) Growth performance and carcass traits of Ovin Martinik lambs fed various ratios of tropical forage to concentrate under intensive conditions. Small Ruminan Research, 75: 162-170.

23. Lawrence TCJ, Fowler VR (1998) Growth of farm animals. CABI publishing London. pp. 271-273

24. Pena F, Cano T, Domenech V, Alcalde MJ, Martos J, et al. (2005) Insluence of sex, slaughter weight and carcass weigh on non-carcass and carcass quality in segurena lambs. Small Ruminant Research, 60: 247-254.

25. Abebe Tafa, Solomon Melaku, Kurtu JP (2010) Supplementation with linseed cake wheat bran and (Linum usitatissimum) cake and/or wheat bran on feed utilization and carcass characteristics of Arsi-Bale sheep. Tropical Animal Health Production, 42: 677-685. 